Group 1: BNP value 0 to 500, of 25 babies 11 had at least 1 course of Ibuprofen of which 2 babies PDA closed, 9 needed ligation. Of the 25 babies 14 had contraindications for medical treatment of which 6 babies needed PDA ligation.

Group 2: BNP value of 501 to 1000, of the 4 babies all were treated with Ibuprofen only 2 babies PDA closed and 2 babies PDA needed ligation.

Group 3: BNP value of 1001 to 2000, of the 2 babies all treated with Ibuprofen 1 baby's PDA closed and 1 baby's PDA needed ligation.

Group 4: $\mathrm{BNP}>2000$, of 3 babies 2 were treated with Ibuprofen, PDA not closed needing ligation and 1 baby not treated with PDA closed.

Conclusion In our study group 59\% (20/34) of babies with PDA needed ligation. BNP level did not predict severity or early referral for PDA ligation in our study group. We need further study with large sample and randomization to support our study conclusion.

\section{SPONTANEOUS CLOSURE OF PATENT DUCTUS ARTERIOSUS IS PRESUMABLE IN VERY LOW BIRTH WEIGHT INFANTS}

doi:10.1136/archdischild-2012-302724.1154

1,2J Sirc, 'J Kucera, 1,2J Semberova, ${ }^{1,2 Z}$ Stranak. 'Neonatal Department, Ustav Pro Peci o Matku a Dite; ${ }^{2}$ Third Faculty of Medicine, Charles University, Prague, Czech Republic

Background and Aims Emerging evidence suggests, that routine pharmacological or surgical closure of patent ductus arteriosus (PDA) is not beneficial for preterm infants. Informations about natural closure of ductus are lacking. Aim of the study was to evaluate untreated preterm infants with PDA.

Methods Retrospective observational study. Very low birth weight infants born during the 18 months period were enrolled. Only babies with severe signs of hemodynamically significant PDA were treated. All patients were followed until closure of PDA (clinically or echocardiographically approved).

Results 198 infants with mean birth weight $1113 \pm 690$ grams and mean gestation age $28.4 \pm 7$ weeks were eligible for the study. 22 $(12 \%)$ died before discharge for morbidities directly unrelated to PDA. 13 patients were treated -6 with ibuprofen and 8 were ligated. One neonate had residual flow through the PDA after ligation. 15 (7.5\%) have been discharged with PDA. From them, 8 had spontaneous closure in the first year of corrected age and 1 in the second year. 6 infants have a small, hemodynamically nonsignificant PDA and are in cardiology follow up.

Conclusions Routine treatment of PDA should be abandoned. Chance of spontaneous closure is likely during the first year of corrected age. Cardiological and long term neurological follow up is needed for infants with PDA.

\section{SURGICAL LIGATION OF PATENT DUCTUS ARTERIOSUS IN PRETERMS LESS THAN 30 WEEKS GESTATION IN A TERTIARY NEONATAL UNIT}

doi:10.1136/archdischild-2012-302724.1155

R Kumar, L Podugu, SV Rasiah. Department of Neonatology, Birmingham Women's NHS Foundation Trust, Birmingham, UK

Background Patent ductus arteriosus is inversely related to gestational age. It remains a significant morbidity and challenge to manage in extremely preterm babies. Medical therapy reduces the need for surgical ligation.

Aim To audit our management of PDA and the need for surgical ligation.

Methods The Badger database was interrogated for babies less than $30+0$ weeks gestation who had a PDA. Their management and outcomes were audited over a 3 year period from 01/04/09 to 31/03/12

Results In the last 3 years, there were 300 babies less than $30+0$ weeks gestation who were admitted to our tertiary neonatal unit. PDA was confirmed on echocardiography in 190 (63\%) babies. 72 (38\%) babies were treated with Indomethacin (62 complete and 10 incomplete course: 5 renal impairment, 3 thrombocytopenia and 2 NEC). 25 (13\%) babies had a surgical ligation of their PDA (The median gestational age at birth was 24 weeks and median birth weight was 725 grams). 13 (52\%) babies who underwent ligation, received at least one complete course of Indomethacin. Median age at ligation was 30 days of life. There was no surgical morbidity or mortality from the PDA ligation. 67 babies died and 233 babies were discharged home. 25 babies needed home oxygen of which 21 previously had a significant PDA.

Conclusion Despite medical therapy, there is a small population of extremely preterm babies who have a recalcitrant PDA that need surgical ligation. Early identification with serial echocardiography and proactive management of these babies might improve their respiratory morbidities.

\section{HYPOXIC PERINATAL CARDIOMYOPATHY-DIAGNOSIS AND EVOLUTION}

doi:10.1136/archdischild-2012-302724.1156

'L Dimitiru, ${ }^{2} \mathrm{Ag}$ Dimitiru, ${ }^{3} \mathrm{M}$ Stamatin. ${ }^{1}$ Pediatric Cardiology, Medex Medical Center; ${ }^{2}$ Pediatric Cardiology: ${ }^{3}$ Neonatology, University of Medicine and Pharmacy, lasi, Romania

Purpose To present the main aspects of myocardial injury secondary to perinatal hypoxia.

Methods/patients 88 newborns aged 0-14 days, normal birth weight, with perinatal hypoxia (Apgar score 3-7), receveing resuscitation, without major congenital heart diseases. All cases: clinical exam, ECG, chest X-ray (Rx.CT), Doppler echocardiography (ECHO). Most of patients were evaluated and after 6 months.

Results The patients had mainly signs of neurological post hypoxic suffering, 8 cases signs of severe heart injury (cardiomegaly, respiratory distress, cyanosis, peripheric hypoperfusion), other cases: systolic murmur (64) and signs of PPHN (8). Chest X-ray: cardiomegaly (32). ECG: severe left ventricle (LV) repolarization disturbances and low voltage of ORS complexes (37), without ischemic changes. ECHO at 2-7 days of life: * the absence of severe congenital cardiac anomaly; *permeability of foramen ovalae (100\%); mild to severe tricuspid insufficiency, RV and RA dilation (29); sometimes rightleft shunt through the FO *myocardial hypertrophy (42) mainly IVS(29), signs of PPHN(6); increased myocardial performance index (44 cases), the systolic dysfunction (5) and severe LV diastolic dysfunction (45 cases). New evaluation at 6 months showed; reduction of the myocardial hypertrophy and of tricuspid regurgitation, normal LV systolic and diastolic function.

Conclusions The perinatal hypoxia can induce a important myocardial injury as hypoxic ischemic myocardopathy or transient post hypoxic hypertrophic cardiomyopathy $(62.2 \%$ of patients), the signs of cardiovascular suffering missing often. Echo is the main method for diagnosis and follow up of perinatal hypoxic cardiomyopathy and is necessary performed from the first week of life.

\section{A REPORT OF TWO CASES OF GLUCOCORTICOID ASSOCIATED CARDIAC DYSFUNCTION IN NOONAN SYNDROME}

doi:10.1136/archdischild-2012-302724.1157

${ }^{1} \mathrm{M}$ Boyle, ${ }^{2} \mathrm{M}$ Cotter, ${ }^{1} \mathrm{O}$ Franklin, ${ }^{1} \mathrm{~A}$ Foran. ${ }^{1}$ Neonatology; ${ }^{2}$ Haematology, Rotunda Hospital, Dublin, Ireland

Background and Aims To review the potential exacerbating factors of cardiac function in 2 cases of Noonan syndrome. 